\title{
ARQUITECTURA POÉTICA Y ASCENSIÓN MUSICAL: YOLANDA OREAMUNO EN CONCIERTO CON EUNICE ODIO
}

\author{
Jorge Chen Sham
}

\begin{abstract}
RESUMEN
En tanto representación escultórica y arquitectónica, el poder de convocatoria de la Poesía se despliega por medio de sensaciones tactiles o visuales, al moldelar y dar forma a un material dentro del espacio de la página. También la Poesía puede, con el lenguaje, tallar una figura humana o levantar un edificio. Yolanda Oreamuno y Eunice Odio saben manejar la proporción, la perspectiva y el volumen como hábiles arquitectas en los dos textos que ponemos en concierto, "Misa de ocho" y El tránsito de fuego, respectivamente.

Palabras clave: Yolanda Oreamuno, Eunice Odio, "Misa de ocho", El tránsito de fuego, arquitectura poética.
\end{abstract}

\begin{abstract}
In as much sculptural and architectonic representation, the power of the call of poetry unfolds by means of tactile or visual sensations upon molding and giving form to a material within the space of a page. In addition, poetry can, with language, carve out a human figure or raise a building. Yolanda Oreamuno and Eunice Odio understand how to manage proportion, perspective and volume as capable architects in the two texts that we put in concert. "Eight O'clock Mass" and "The Path of Fire" respectively.

Key Words: Yolanda Oreamuno, Eunice Odio, "Eight O'clock Mass", "The Path of Fire", architectural poetry.
\end{abstract}

Las relaciones entre la literatura y las demás artes tienen una larga tradición en nuestra literatura occidental y han recibido también un extenso análisis desde Platón y Aristóteles. En el pensamiento griego, la mimesis literaria en cuanto TEKJNE se emparentaba con las otras artes por su carácter delectable y por sus efectos sugestivos de lenguaje. Debido a esto no es casual que la asociación de la palabra poética con la música esté en el origen mismo de la

\footnotetext{
Jorge Chen Sham. Profesor de la Escuela de Filología, Lingüística y Literatura, Universidad de Costa Rica. San Pedro, San José, Costa Rica.

Correo electrónico: jorgechsh@yahoo.com
}

Recepción: 17- 9- 2008

Aceptación: 23- 10- 2008 
poesía, en cuanto a que el ritmo y el metro despliegan el recurso de la armonía fundante del verso. Ahora bien, desde el clásico Ut Pictura Poesis, que la tradición griega aprehende como esa manera de transponer los sentidos y conseguir un lenguaje poético transformado en pintura verbal, también los poetas han intentado acercar la Poesía a la representación escultórica y arquitectónica, entre otras artes (Welleck y Warren 1979: 150).

Esta interdependencia es posible por el despliegue de sensaciones táctiles o visuales que tanto la escultura o la arquitectura convocan. Si estas artes moldean y dan forma a un material dentro de un espacio, es porque el trabajo de la piedra o el mármol para tallar una figura humana o levantar un edificio exigen el manejo de la proporción, la perspectiva y el volumen, que son categorías eminentemente espaciales. De la misma manera, el poeta puede trabajar la palabra para tallar ya sea un busto, ya sea un fresco en bajorrelieve en el caso de la escultura ${ }^{1}$; ya sea para construir un palacio o un templo en el caso de la arquitectura. No estamos planteando tanto una adecuación de lo literario a estas artes como si fuera una simple transposición artística, ni tampoco como relación intertextual en el caso de un texto literario se asocie a otra obra artística identificable; todo lo contrario, nuestro interés radica en el grado de representación musical, visual, escultórica o arquitectónica que el texto poético suscita o proyecta, el cual depende del régimen de descodificación que, por medio de los sentidos y de las imágenes forjadas, evidencie. Por ello, la constitución y la estructura interna del texto poético así construido remite a una forma dinámica en el sentido de que "más que en la arquitectura los diferentes materiales empleados, en [la literatura] lo estructurado, lo construido, lo formado interviene cualitativamente en la forma, en la construcción, en la estructura misma" (Alonso 1969: 90)².

A este respecto, según algunos críticos, la tesis de que el poema es una estructuración conduce a subrayar la construcción/modelización de un volumen arquitectónico o musical, gracias, precisamente, al valor eufónico de las estructuras rítmicas y métricas en un poema (Hidalgo 1999: 145); la plasticidad se logra en esa convocatoria de lo cromático-visual, lo auditivo-melodioso y lo táctil-sensorial dentro de un efecto compositivo-estructural propio de lo estético. Según Narciso J. Hidalgo, plantear una arquitectura poética supone tomar en consideración que el ritmo y la musicalidad del lenguaje poético "se articulan o desarticulan por el sonido, al margen de su representación gráfica" (1999: 146); sin embargo, reducido a lo eufónico la clave del volumen poético implicaría dejar por fuera la representación visual o táctil que lo acompaña y, principalmente, el diseño compositivo del texto. No solo se trata de sentir, ver, palpar, oír o gustar por medio, gracias o con las palabras, sino de que el lenguaje poético, en tanto experiencia estética, convoca la alusión, la asociación y la sugerencia, propias del nivel connotativo y de la función emotiva del lenguaje.

En lo que se refiere a Yolanda Oreamuno, tiene razón Rima de Vallbona en plantear el trabajo de la metáfora proustiana (1995: 70-1), el cual hace que sus relatos se caractericen por la neutralización de la temporalidad y la emergencia de una metáfora continuada, por cuyo procedimiento su narrativa llega a ser una prosa poética, de una riqueza estilística, sugerente, tanto por su apelación a lo figurativo en esa unión de lo plástico como de lo musical. Desde este punto de vista, "Misa de ocho" es un relato que nos obliga a repensar el régimen de descodificación semiótica en Oreamuno, ya que la experiencia estética a la que se enfrenta el personaje protagónico, ante ese despliegue de luz, color, sonido y armonía no lo hace un simple espectador pasivo de la misa, sino que llegamos a su participación en donde la transformación 
estética y, por lo tanto, espiritual, se acrecienta y lo envuelve. Precisamente en la descripción inicial de la catedral domina el efecto de la luz que entra por las puertas laterales:

\footnotetext{
Dos puertas grandes que son el ambiente de la iglesia; en estas dos puertas la luz se detiene [...]; esta luz de mañana de verano, se hace densa y tilinte dentro del marco de las puertas, hasta ser un espejo; no un espejo que refleja la gente que va llegando muy lentamente, ni las cabezas inclinadas bajo la toalla, sino un espejo que se refleja sobre todos ellos (139).
}

Observemos cómo el protagonista de la escena es la luz y no los seres humanos. Localizado, suponemos, en el centro de la catedral por esa apreciación de las puertas laterales, el yo que contempla personifica la luz y, en ese juego especular, los efectos de luz rebotan e inundan la inmensidad del espacio hasta llegar a iluminar "las molduras doradas del altar" (140). En un gran despliegue de la luminotecnia, el espacio se ilumina como si fuera un escenario para realizar el theatrum mundi de la tradición occidental, pues la luz da paso al color gracias a una técnica parecida al tecnicolor; así el color da vida: "Ha salido el ambiente y ha entrado el color./ El color que entra es quién vestido de esta manera" (140). Absorto frente a los efectos lumínicos de los vitrales de la catedral, la celebración de la misa inicia al mismo tiempo que la música: la música angelical que escucha corre paralela tanto a la luz como a la eucaristía, por lo que la contemplación se transforma en el régimen discursivo propio de "Misa de ocho": "La misa y la música han empezado simultáneamente. Paralelas e iguales, se desarrollan respondiendo la una a la otra, imitando la una a la otra. A ratos la misa es música y otras veces, la música es ceremonia mística" (140-1).

Si como plantea Luis A. Jiménez en relación con la arquitectura en tanto "el diseño más visible y público de las Bellas Artes [que] ha causado la atracción de la mirada artística en el mundo de la construcción y la representación del espectáculo" (1995b: 86), la configuración arquitectónica de "Misa de ocho" no debe soslayarse ni pasar desapercibida, pues toda representación de las artes convocadas en el relato, luz, color, sonido y decorado, forman parte de una mimesis que crea un conjunto creativo, capaz de representar el texto y dar su configuración sígnica. De esta manera, no es inocente el paralelismo, no tanto entre la música y la misa según indica el sujeto que contempla, como el juego de luz/color y la música coral. Es aquí en donde la metáfora proustiana en tanto suplemento textual cobra todo su interés crítico. Veamos cómo se describe los inicios del coro musical:

\footnotetext{
El tema musical sale a tiempo y acorde de un hoyo en el que hubiera estado esperando inútilmente y se mantiene alterando sólo su superficie con pequeñas ondulaciones que convergen al centro. Así dura un rato. De pronto, toda la melodía se repliega nerviosa y temblante a la circunferencia y el tema es cogido en el aire por una voz alta y aguda que se eleva como una columna de humo en un aire densamente tranquilo, recta, con leves circunvoluciones en la base. La nota sube por allí como una cuerda que hubiera arrojado ella misma y que milagrosamente se hubiera sostenido en el aire. Ya parece llegar a lo más alto. Sigue subiendo. Ya llega. Y ahora baja (141).
}

La cita es sumamente larga; pero es imposible de cortar por esa manera en la que Yolanda Oreamuno maneja las imágenes en una sucesión perfecta y entrelazada. Si observamos con atención, la música se comporta como la luz al inicio del relato: de las puertas laterales se dirige hacia el centro de la catedral y de ahí como si conformara un ángulo de reflexión sube de nuevo; lo mismo ocurre con la música, localizada en el centro inunda los espacios gracias a la inmensidad del aire. El movimiento de ascensión musical y su correspondiente descenso están en el relato para subrayar, con esa técnica propia del contrapunto, la elevación mística. No sólo la luz y el sonido se elevan, el mismo ascenso es producido por las columnas verticales de la catedral que hacen que el régimen visual sea el de la espiral. Ante tal espectáculo de los 
sentidos, la arquitectura poética obliga al sujeto que contempla a elevarse y llevarse por los sentidos, hasta llegar a un clímax poético:

\footnotetext{
A bailar. Sí. ¿Por qué no he de bailar yo? ¿Por qué no he de bailar en la imaginación como otros rezan en la boca solamente? ¿Por qué no?

Hay que bailar esta danza mística o pagana; hay que dejarse tocar por la música de un lado, de otro, hay que dejar que ella, creación imaginativa máxima, haga este baile que le dedico a Dios (143).
}

El sujeto absorto rechaza toda prohibición; su espíritu vibra de emoción y demanda que su cuerpo lo siga en una celebración exultante, de alabanza total, cuya significación auténtica radica en su origen trascendental de la experiencia religioso-poética. Ello nos remite a Platón en su diálogo Ion o De la Poesía, en donde se plantea la raigambre divina de la Poesía y se la asocia al delirium tremens, a esa manifestación de lo sagrado. La divinidad, por medio de las Musas, se posesiona del alma del poeta y le inspira; dice Sócrates a Ion en este sentido:

\footnotetext{
En igual forma, la musa inspira a los poetas, éstos comunican a otros su entusiasmo, y se forma una cadena de inspirados. No es mediante el arte, sino por el entusiasmo y la inspiración, que los buenos poetas épicos componen sus bellos poemas. Semejantes a los coribantes, que no danzan sino cuando están fuera de sí mismos, los poetas no están con la sangre fría cuando componen sus preciosas odas, sino que desde el momento en que toman el tono de la armonía y el ritmo, entran en furor, y se ven arrastrados por un entusiasmo igual al de las bacantes [...] (1957: 96).
}

La contemplación poética interpela esas fuerzas trascendentales y, al demostrar que su revelación no es de factura humana porque se nutre de una posesión (delirio) que arrastra al ser humano, "Misa de ocho" nos conduce a un movimiento exotópico, el sujeto se sale de sí mismo. En Ion o De la Poesía, Platón subrayaba el origen divino y trascendental de la inspiración poética, razón por la cual no podía explicarse bajo leyes humanas o conceptos de verdad. El poeta sería un iluminado y un enardecido por una energía vital y, al ser instrumento de los dioses, está en la misma categoría que otros tipos de oficiantes, como nos recuerda Roberto Cañas: "La poesía es el efecto de una posesión divina semejante al frenesí de los sacerdotes y profetas" (1995: 82).

Por ello también, al reivindicar ese salirse de sí mismo para abrogarse el daimon de la creación, desenfreno y locura se dan la mano y promueven el enardecimiento del espíritu y una energía liberadora ${ }^{3}$. Tales rasgos de la locura poética, que Platón distingue en el Fedro como diferente de otras locuras, por ejemplo la profética o la ritual-religiosa, es sin duda significativa para estructurar el paralelismo antitético que desarrolla en la dispositio del relato a manera de arquitectura narrativa. Por esa razón, "Misa de ocho" nos revela la clave metapoética de la escritura oreamuniana gracias a una arquitectura lírica y una ascensión musical. Lo mismo sucede con Eunice Odio en su Tránsito de fuego, en donde la construcción de la catedral en la Tercera Sección del libro tiene el mismo estatuto que en Yolanda Oreamuno.

Ahora bien, ¿por qué una catedral? El simbolismo de una catedral, nos lo recuerda Chevalier y Gheerbrant, está asociado al templo como un lugar de sacralidad y de la emergencia de lo trascendental. Pero no se trata de cualquier catedral; en nuestro imaginario occidental la representación por antonomasia de la catedral se asocia con las grandes y exquisitas catedrales góticas ${ }^{4}$, las cuales se impulsan hacia el Cielo como alabanza a la grandeza de la divinidad. Antonio García Berrio señala que la catedral medieval, es decir, la gótica, corresponde una concepción en la que enseñanza y deleite se conjugan para que se produzca una exaltación de la voluptuosidad formal en esa consideración con lo sublime religioso. La pintura y la escultura se integran en esa suma de la catedral gótica, en la que "el 
inevitable complejo de fuga moralizadora y deleite cristalizaba" (García Berrio 1973: 25) una exaltación de las formas al servicio de un ideal de trascendencia divina.

Símbolo entonces de la inmensidad divina y de la magnificencia de lo trascendental, la catedral gótica pondera el valor de la creación en su esplendor espiritual y material. No es casual que sea el símbolo por excelencia de la creación humana el que escoge aquí Eunice Odio, una nueva creación del cosmos gracias a la invención del lenguaje poético por parte del demiurgo creador Ion en el Tránsito de fuego; oigamos sus palabras que conjugan el poder y el conjuro:

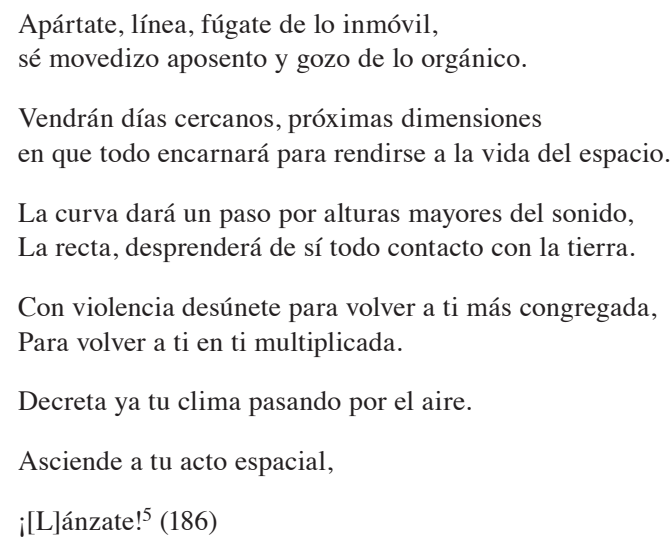

Ion performa el lenguaje al estilo de los mitos genésicos en los que el decir y el hacer se imbrican. El dinamismo y la movilidad del aire se instauran en esas líneas arquitectónicas que se levantan desde los cimientos del lenguaje y están acompañados por las curvas de sonidos que se elevan por el espacio. De esta manera, como si fuera un arquitecto que traza el plano del edificio por venir, Ion se vale de rectas y curvas para conjurar, en ese acto poético, la magia de la creación. Vemos, entonces, surgir hacia arriba, puesto que la verticalidad domina en unos versos que, por su misma distribución tipográfica en una libre extensión de las líneas, invitan a una progresión; se trata de sugerir "el énfasis, la velocidad de lectura y la situación de las pausas [...] más adecuadas a la elocución del poema” (Martínez 1996: 57) para lograr ese clímax de los dos últimos verbos en imperativo: "Asciende” y “i[L]ánzate!”. Así, del plano orgánico del edificio pasamos a la cantera donde se encuentra la obra en construcción. Lo primero que llama la atención es el símbolo escogido por Eunice Odio, la piedra; dice Ion al respecto: "Mañana la piedra desencarnada,/ libre ya de su peso, parirá/ sin pecado/ un soplo" (188).

La piedra angular de la que se construyen los edificios es viva; su simbolismo remite al artificio de la creación y al soplo divino de la voz creadora. En esta parte del poema será Ion, junto con Logos y con Arkhos, el encargado de levantar la catedral. No es casual que estos personajes acompañen a Ion en esta nueva creación. Como si fuera una cantata a tres voces emerge, gracias a las metonimias arquitectónicas, la catedral. Veamos a Ion intercambiar un diálogo de gran sentido espacial con Logos:

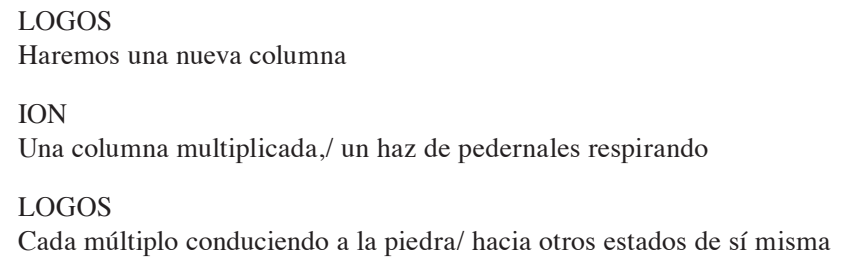




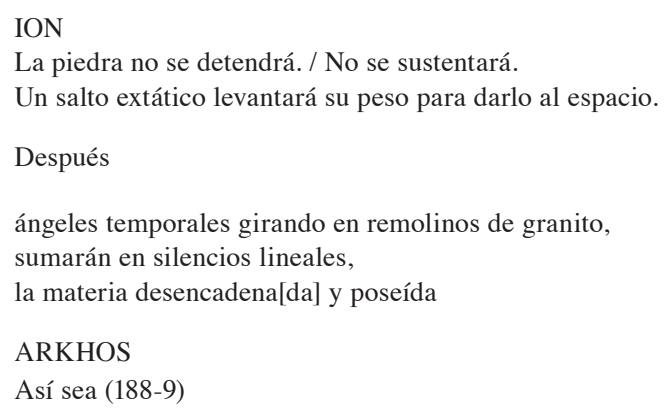

En un arrebato en el que las palabras de uno y otro se van sumando en un ritmo in crescendo, lo cual subraya la intensidad y el ímpetu de su plan creador, columna y piedra se alinean para hacer surgir el edificio. Pensamiento y acción se funden en un acto de construcción en el que, de nuevo, el movimiento y el dinamismo refuerzan esa sensación de espiral, de ascenso vertical y progresivo. Luego es Arkhos el encargado de rematar esta obra en construcción, aportando otros dos elementos constitutivos de la construcción, el muro y la bóveda:

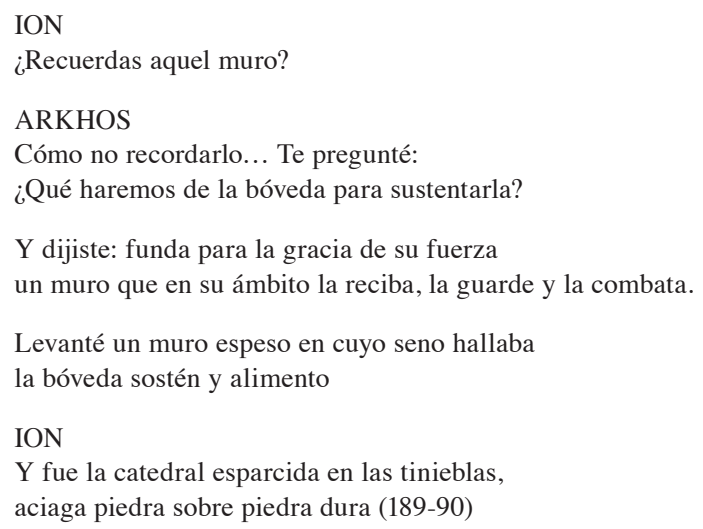

La catedral va surgiendo en la medida en que Ion, Logos y Arkhos la diseñan. No hay poder más grande del lenguaje en el Tránsito de fuego, cuando la materia (la piedra) y las técnicas de construcción (línea, columna, muro, arco y bóveda) se enuncian en un proyecto-plano que se piensa pero que, a la vez, se construye, porque emerge delante de nuestros ojos de lectores. Este encadenamiento/ progresión es el que intenta reproducir la serie de verbos en futuro y en pretérito simple, por cuanto este último tiempo indica la acción acabada. La verticalidad y el dinamismo del movimiento se apropian de un lenguaje que intenta expresar el poder mágico de la Poesía, en un acto que es éxtasis ascensional. No cabe mayor concierto, es decir, de concertación de voces entre Yolanda Oreamuno y Eunice Odio; la arquitectura y la música están al servicio de una concepción metapoética del lenguaje en textos de harto valor estético.

\section{Notas}

1. Se trata de esculpir con el lenguaje como ha señalado Luis A. Jiménez para el caso de los retratos que hace el poeta cubano Julián del Casal, poeta modernistas, que esculpe las figuras retratadas (1995a:117). 
2. Ello conduce a Amado Alonso a subrayar que los materiales de una pintura o de un edificio no tienen la misma función que en la poesía, en donde los materiales evocados se emplean dentro de un sistema expresivo, es decir, de construcción por medio de la representación pictórica, arquitectónica o musical.

3. Y si sabemos leer el texto de Platón, también libidinal. Por otra parte, Cañas nos recuerda que el término en griego clásico que corresponde a la locura es $\mu \alpha v \iota \alpha$ (manía), pero se trata de una locura en tanto don que proviene de los dioses (Cañas 1995: 83).

4. En un nota periodística del Excelsior de México, con el título de "Recital de Eunice Odio", del sábado 1 de marzo de 1958, se indica que, el jueves pasado, la poeta dio un recital en Galerías Excelsior de la larga sección "Los trabajos de la catedral": "El poema es una exploración dinámica por el conjunto de la catedral gótica, la que según Eunice es piedra miliar de la civilización del Renacimiento. En dicho poema hablan personajes entregados a la tarea de construir la aérea catedral" (2-B).

5. Corrijo lo que me parece una errata en la edición de las Obras Completas de Eunice Odio.

\section{Bibliografía}

Alonso, Amado. 1969. Materia y forma en poesía. $3^{\text {a }}$ ed. Madrid: Editorial Gredos.

Cañas Quirós, Roberto.1995. "La poesía en Platón (I Parte)". Revista de Filosofía de la Universidad de Costa Rica. 33 (80): 79- 85.

García Berrio, Antonio. 1973. Significado actual del formalismo ruso (La doctrina de la escuela del método formal ante la Poética y la Linguística modernas). Barcelona: Editorial Planeta.

Hidalgo, Narciso H. 1999. "Arquitectura rítmica y son en Los motivos del son". Monographic Review/ Revista Monográfica. 15: 145- 60.

Jiménez, Luis A. 1995a. "Bustos: la representación del panteón de la nación letrada en Cuba". Julián del Casal en el nuevo milenio. Luis A. Jiménez (ed.). Managua: PAVSA, 117- 34.

1995b. "Ut Architectura Poesis: La obra de Julián del Casal". Círculo: Revista de Cultura. 34: 86- 94.

MartínezFernández,JoséEnrique.1996.Elfragmentarismopoéticocontemporáneo(Fundamentos teórico-críticos). León: Secretariado de Publicaciones de la Universidad.

Odio, Eunice. 1996. Obras Completas. Tomo III. San José: Editorial de la Universidad de Costa Rica/ Universidad Nacional. 
Oreamuno, Yolanda. 2003. Valle alto. San José: EUNED.

“Recital de Eunice Odio”. Excelsior de México, sábado 1 de marzo de 1958: 2-B.

Platón. 1957. “Ion o De la Poesía”. Diálogos escogidos. Buenos Aires: El Ateneo.

Vallbona, Rima de. 1995. La narrativa de Yolanda Oreamuno: Estudio crítico por Rima de Vallbona. Textos originales de Yolanda Oreamuno. San José: Editorial Costa Rica.

Wellek, René y Austin Warren. 1979. Teoría literaria. $3^{\text {a }}$ reimp. Madrid: Editorial Gredos. 